\title{
A Study on Levels of Inquiry: \\ A Quantitative Descriptive for Analyzing Science Learning on Linear Motion Topic
}

\author{
Novia \\ Universitas Tadulako \\ Palu, Indonesia \\ vhiea..cweetz@yahoo.com
}

\author{
Riandi \\ Universitas Pendidikan Indonesia \\ Bandung, Indonesia
}

\begin{abstract}
This paper describes how the levels of inquiry aspects are developed by using levels of inquiry model (LOI). This study applies LOI in science learning on the matter of linear motion. The levels of inquiry within the inquiry spectrum are shown: discovery learning, interactive demonstration, inquiry lesson, inquiry lab (3 types-guided, bounded, and free), realworld applications ( 2 types-textbook and authentic), and hypothetical inquiry ( 2 types-pure and applied). This study limited levels of inquiry till the inquiry lab. The instrument used ware worksheets, videos transcript and feasibility levels of Inquiry model. This study uses quantitative descriptive and research design is one group pretest-posttest design. Samples in this study were 30 students on one of junior high school in Bandung. Results show that there is an increase in the quality of levels of inquiry aspects every meeting. The highest attainment is an interactive demonstration and the lowest is inquiry lab. The percentage of right student worksheets more than $75 \%$ every meeting. The conclusion is quantitatively there is an increase in an aspect of levels of inquiry. The writer recommends For teachers: the levels of inquiry model can be used as an alternative learning in science learning so that the students can construct their knowledge independently. 2) For other researchers: It would be better if the instrument student's worksheet on lives of inquiry is made to be more questions of each aspect so that it can be seen its consistency.
\end{abstract}

\section{Keywords-Levels of Inquiry; Science Learning; linear motion}

\section{INTRODUCTION}

Learning science should be oriented on presenting concrete and actively involve students in terms of mental and physical, applicative capabilities, development of thinking skills, curiosity, and development of caring and responsible attitude towards the social and natural environment. Students learn based on activities according to developmental level in order to explain the events that occur in our daily lives [1]. Students are directed to conduct inquiry and act so as to obtain a deeper understanding of nature around.

Understanding the nature of science is conceptual should be able to direct one's view on the essential meaning of the learning process of science. The true meaning of teaching and learning in science education should be defined as the process of forming competence, is not just a transfer of knowledge from teacher to students is one with the inquiry.
The inquiry has been regarded as an important and efficient strategy to promote science learning. Inquiry facilitates student learning, work and ask questions to better than traditional laboratory approach [2]. But in reality the students still have substantial issues regarding the scientific reasoning of inquiry, such as difficulty in stating a hypothesis that can be tested, choose the right variables, determine the relationship between these variables, designing experiments to test convince them hypotheses, draw the right conclusions from the experiment, connecting with the hypothesis of experimental data, and interpret the results appropriately theory [3]. Thus, the inquiry which should encourage scientific reasoning of students as one of the main goals of science education is not met. [4], [5].

Based on the interview in one of the junior high school in Bandung, which is one of the science teachers stated that classroom learning is not based inquiry as a whole because it is still rare to experiment with, other than that there is difficulty in developing scientific reasoning and critical thinking because the type of questions are used still rote form and matter, without ever trying to use standardized tests. So it does not require students with higher level thinking and tends to just memorize formulas. Occasionally conducted an inquiry into learning but not fully engage students in scientific inquiry and plan an experiment. Though scientific investigation and knowledge content interconnected to underlie the development of scientific thought.

An alternative solution is seen to solve the problem is applying a model of inquiry. There have been many teachers who incorporate different approaches such as discovery learning inquiry, guided inquiry, or free inquiry in science learning. But the fact that the teacher just applies it without any comprehensive understanding of the use [6]. As a result, many of the approaches of inquiry in schools that applied intermittently (disconnected process), the process is not systematic (random inquiry processes) and often fail to train intellectual processes skills that are used to develop students' understanding [6]; [7]

Carl J. Wenning develops inquiry unipolar circuit consisting of six levels starting with the basic level to the highest known levels of inquiry. The levels in between, Discovery Learning, Interactive Demonstration, Inquiry lesson, inquiry Lab, Real Word Application and hypothetical Inquiry [6]. Stages levels of inquiry can be seen as in Fig. 1. 


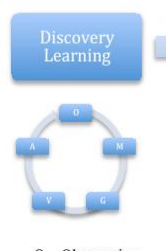

O-Observation
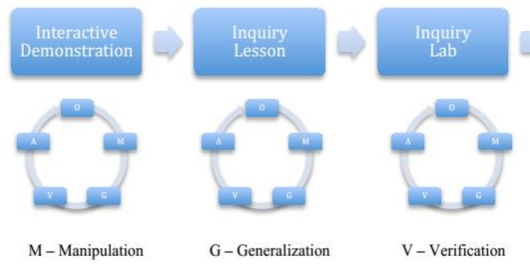

G-Generalizatio

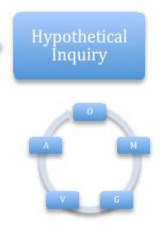

A- Application

Fig. 1 Stages levels of inquiry

Levels of Inquiry had a major pedagogical goal in every aspect that can be appreciated by teachers and students. Wenning divides the inquiry based on the fact that most teachers have not been could applying inquiry-based learning properly, so it needs understanding about inquiry learning. Basically, the division of inquiry to follow the level of human intelligence and control teachers in learning activities. Picture LOI relationship, level of intelligence and control teachers [6] can be seen as in figure 2 .

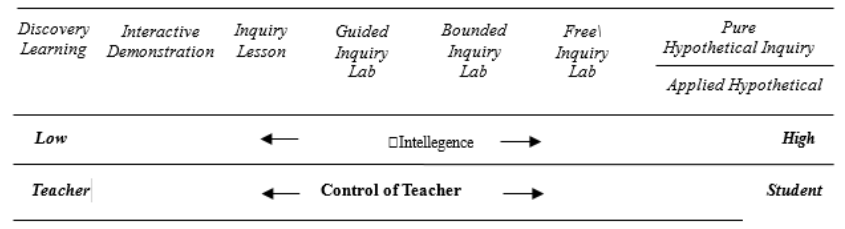

Fig 2. Diagram of Inquiry Hierarchy [8]

The Inquiry processes are not taught partially, but in a coherent whole from the most easily accepted by students Discovery Learning (DL) in this case the dominant role of the teacher to Pure / Applied Hypothetical hardest where students were a very dominant role. LOI learning sequence in the figure shows that in every stage of inquiry requires certain conditioning that is intellectual and controlling factor.

Levels of inquiry in question in this research are the inquiry model described by [9]. In general, levels of inquiry is a learning model that is implemented comprehensively and systematically, aiming to increase students 'conceptual understanding and to develop students' understanding of scientific inquiry and the nature of science. Stages in the levels of this inquiry are the discovery learning, interactive demonstration, inquiry lesson, laboratory inquiry, real-world application, and hypothetical inquiry. However, in this study, the stages of levels of inquiry are limited to the stage of four stages, namely the discovery learning, interactive demonstration, inquiry and guided inquiry laboratory lesson on the grounds adjusted to the level of research subjects used to think that junior high school students. The fourth stage is applied in the learning process during the three meetings. To look at the implementation levels of inquiry used observation sheet implementation levels of inquiry and the transcript of the video recording application levels of inquiry.

Each stage in the levels of inquiry is closely related to a single stage process intellectual skills. The higher stages of levels of inquiry are applied, the more complex the process of intellectual ability skills required. Focus intellectual skills are practiced process at every stage.

In this study, a topic studied movement is the sense of motion, uniform rectilinear motion, and uniformly accelerated motion. Levels of inquiry are able to train development of intellectual abilities and thinking [7]. In addition, levels of intellectual inquiry are able to train skills that process in every stage of levels of inquiry. The relationship between the stages of levels of inquiry with a description of the activities of students and Intellectual Skills Process can be seen as in Table I.

TABLE I. INTELLECTUAL SKILLS PROCESS

\begin{tabular}{|c|c|c|}
\hline $\begin{array}{c}\text { Levels of } \\
\text { inquiry }\end{array}$ & $\begin{array}{c}\text { Student Activity } \\
\text { Description }\end{array}$ & Intellectual Process Skills \\
\hline $\begin{array}{l}\text { Discovery } \\
\text { Learning }\end{array}$ & $\begin{array}{l}\text { Students develop a } \\
\text { concept based on } \\
\text { direct experience }\end{array}$ & $\begin{array}{c}\text { Rudimentary skills: } \\
\text { Viewing, formulate concepts, } \\
\text { estimate, making inferences, } \\
\text { communicating the results, } \\
\text { classifying or grouping results }\end{array}$ \\
\hline $\begin{array}{c}\text { Interactive } \\
\text { Demonstration }\end{array}$ & $\begin{array}{l}\text { Students are } \\
\text { involved in } \\
\text { explanations and } \\
\text { predictions }\end{array}$ & $\begin{array}{l}\text { Basic skills: } \\
\text { Predict, explain, predict, acquire } \\
\text { and process data, formulate and } \\
\text { revise scientific explanations } \\
\text { using logic and evidence, identify } \\
\text { and analyze the explanations } \\
\text { obtained from the demonstration. }\end{array}$ \\
\hline inquiry Lesson & $\begin{array}{l}\text { Students identify } \\
\text { scientific principles } \\
\text { and or relationships }\end{array}$ & $\begin{array}{c}\text { Intermediate Skills: } \\
\text { Measure, collect and record data, } \\
\text { create data tables observation, } \\
\text { design and conduct scientific } \\
\text { investigations, using technology } \\
\text { and mathematics during an } \\
\text { investigation, describes the } \\
\text { relationship }\end{array}$ \\
\hline inquiry Lab & $\begin{array}{c}\text { Students establish } \\
\text { empirical law based } \\
\text { on the measurement } \\
\text { of variables }\end{array}$ & $\begin{array}{c}\text { Integrated Skills: } \\
\text { Measure, the law establishes the } \\
\text { basic empirical evidence and } \\
\text { logic, design and conduct } \\
\text { scientific investigations, using } \\
\text { technology and mathematics } \\
\text { during the investigation }\end{array}$ \\
\hline
\end{tabular}

Based on the analysis of the curriculum, the application levels of inquiry at the junior level inquiry conducted up to stage lab. On discovery phase of learning, students are given the opportunity to state a fact and describe the phenomenon based on facts. In interactive stage demonstration, the students are given the opportunity to be able to make predictions and use the knowledge they have. At the inquiry stage of the lesson, students are trained to design an investigation to identify the principles or relationships. At the inquiry stage of the lab, the students were given the opportunity to establish an empirical law based on the measurement of variables. The stages in the levels of inquiry in line with scientific literacy competency domain framework covering explain scientific phenomena, evaluating and designing scientific research, and interpret data and scientific evidence.

Application of inquiry in science learning approach should be applied in a systematic, logical, coherent, and gradually in accordance with the student's intellectual capacity and content of the material being taught. Inquiry approach is applied gradually starting from learning which involves the basic capabilities towards the ability of the complex. 


\section{METHOD}

The research method chosen for this study is descriptive quantitative research method. This study describes all the activities, conditions, events, as well as their components and aspects of the picture using the size or frequency. The only element of manipulation or retrieval of data provided only the research itself, which is done through observation, interviews, questionnaires distribution or documentation [2].

Descriptive research is not only to stop the data collection, organization, analysis, and interpretation as well as the withdrawal of the conclusions but continued with benchmarking, looking for similarities, differences, the causal relationship of things due to the discovery of meaning is the focus of the whole process. [10]. This study does not hold manipulation or alteration of the independent variables but describes a condition is. The depiction of the condition can be individual or group and use figures.

The study design used was one group pretest-posttest design. In this design, there is no comparison or control group [11]. In addition, there is a pretest before collecting data so that the results can be known data retrieval is more accurate because it can be compared before and after given data retrieval.

\section{Location, Sample, And Instruments}

Locations used in this study is one of the Junior High School (SMP) in Bandung. population in this study were all seventh-grade junior high school students in the 2014/2015 academic year one junior high school in the city. However, due to limited funds, manpower and time, the researchers simply take a sample of the population. Samples from this study are one that is class VII-VII class $\mathrm{C}$.

The sampling method used in this research is purposive sampling taking a sample of the population members are done with certain considerations. Aspects purposive were taken into consideration that these schools have laboratory facilities are decent, tools experiments in the school are quite complete and haves A accreditation, had a science teacher who was young to become partners of the research as a model teacher, so the researchers assume that school according to data retrieval is done.

The instrument used in this study include observation sheets, transcripts of the video, the assessment rubric student worksheets, and questionnaires.

The implementation of the observation sheet aims to determine the extent to which the implementation of the levels of inquiry conducted by teachers and students during the learning takes place. The learning activities were observed ranging from discovery stage to inquiry learning lab. Implementation sheets on levels of inquiry in this study using the checklist on by Guttman scale (yes-no). If the activities listed on observation sheet accomplished in the implementation of the observer's levels of inquiry provides a checklist in the yes column by a score of one and column with a score of zero.
A video transcript of learning is an encryption dialogues that occur during the learning process by using the model of levels of inquiry are recorded using instructional video. The transcript of this video contains a picture of the interaction of students and teachers during learning. Through this video transcripts, researchers can take important points which can then be analyzed to determine the enforceability of the quality levels of inquiry. In addition, the transcript can be used to support, strengthen and refine the results and analysis.

Rubric Assessment Student Worksheet (LKS) is used to provide the scoring guide LKS. LKS is a sheet of tasks to be completed by students and used as a guide for students in conducting learning activities. LKS contains an overview of each phase of student activity levels of inquiry. LKS is also used to assess the extent to train aspects of levels of inquiry for each sub-topic of motion. So it can be said that has two functions: as a tool in the learning activities and tools for assessing aspects of the LOI at each meeting.

The questionnaire is an instrument that contains a set of questions or a written statement to the respondent to answer. The format of the questionnaire used is a form of expression that should be answered by "yes" and "no" along with the reasons respondents, in this case, the students. In this study, there are two questionnaires were used that questionnaire response of students to teaching science and student questionnaire responses to the model of levels of inquiry.

\section{RESULT AND DISCUSSION}

Researchers took the data of research on the implementation of the learning undertaken by the class teacher with the topic of motion. Class VII C the sample had a science lesson schedule on Tuesday and Friday. The first data retrieval on Friday, April 17, 2015. The formation of the group is carried by randomly teachers and students formed into five groups. During data collection, an observation was done by five people, namely the people as the researchers themselves to observe the activities of the students during the learning activities and observe adherence to the use of the model levels of inquiry and four others observe student activities for each group. So each group was observed by an observer. During the implementation of the study, researchers assessed each activity carried out in the learning process, in terms of adherence to the model levels of inquiry, activities, and attitudes were observed using video recordings and rubric worksheets of each student are observed to determine the development of reasoning and scientific thinking of each meeting. Researchers actually observe and describe all the processes that occur from the beginning until the end of the data collection data retrieval.

The first meeting was held in the science lab, this is because space usually occupied by used by students of class IX in preparation for the UN. In the learning process, students were divided into 5 groups which have 6 members in each group. During the study, all the activities of teachers and students were observed by five observers and dialogue that occurred during the encryption process of inquiry learning levels recorded using a video recorder. 
Overall there are no significant problems in the implementation of learning for teachers and students already studying with models of levels of inquiry, so that teachers and students do it without the burden of assuming new learning model that is alien to them, however, in reality, there is still a shortage of learning implementation, it this is because the model of levels of inquiry does take a long time for habituation in its application.

Based on the implementation of the Levels of Inquiry, can be seen also vote Student Activity Sheet. Activity Sheet Students in this study has several benefits, ie. Therefore, student's worksheet can show aspects of levels of inquiry on each subtopic of motion. Activity Sheet Students in this study has several benefits, i.e. Therefore, LKS can show aspects of inquiry that training levels of reasoning and critical thinking skills. The percentage of students' answers on worksheets as a whole can be seen in Figure 3.

\section{Right Answer Student on LKS}

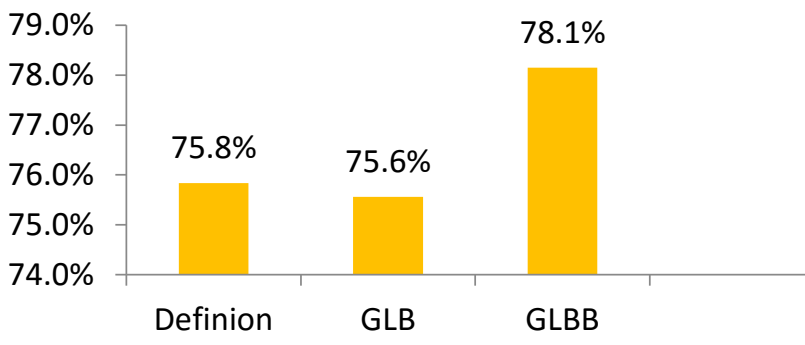

Fig 3. Percentage of Correct Answers Students at LKS

Based on the picture above, it can be seen that the percentage of students the right answer to fill the LKS is more than $75 \%$ for each meeting. This shows that each step in the inquiry trains levels of critical thinking and scientific reasoning, students were able to follow him and be able to answer questions. LKS charging is tailored to the material that is taught at every meeting and separated into LKS 01 and 02 , to mark the limits of demonstration and trial inquiry lab. The percentage of students' answers on worksheets based on subtopic can be seen in Figure 4.

Based on the picture above, it can be seen that the highest percentage of students the right answer in filling in the subtopic LKS understanding aspects of inquiry lab motion is $87.30 \%$, while in subtopics uniform rectilinear motion is the interactive aspect of demonstration $85.1 \%$ and in motion uniformly accelerated discovery learning aspect is $83 \%$.

It is not entirely in accordance with the theory put forward by [12] because the aspect most likely answer students are the highest aspect of discovery learning because on this aspect of the teacher still has a role full control and intellectual experience involve the lowest, will move up until the inquiry lab the highest.

In accordance with pedagogical purposes discovery learning, which students can develop a concept based on the first experience that they get (focus on the active involvement of students in constructing knowledge) then it should most students already understand the concept of motion so that the discovery was the highest earning. This only happens at the last meeting that the Straight Motion Irregularly Changed.

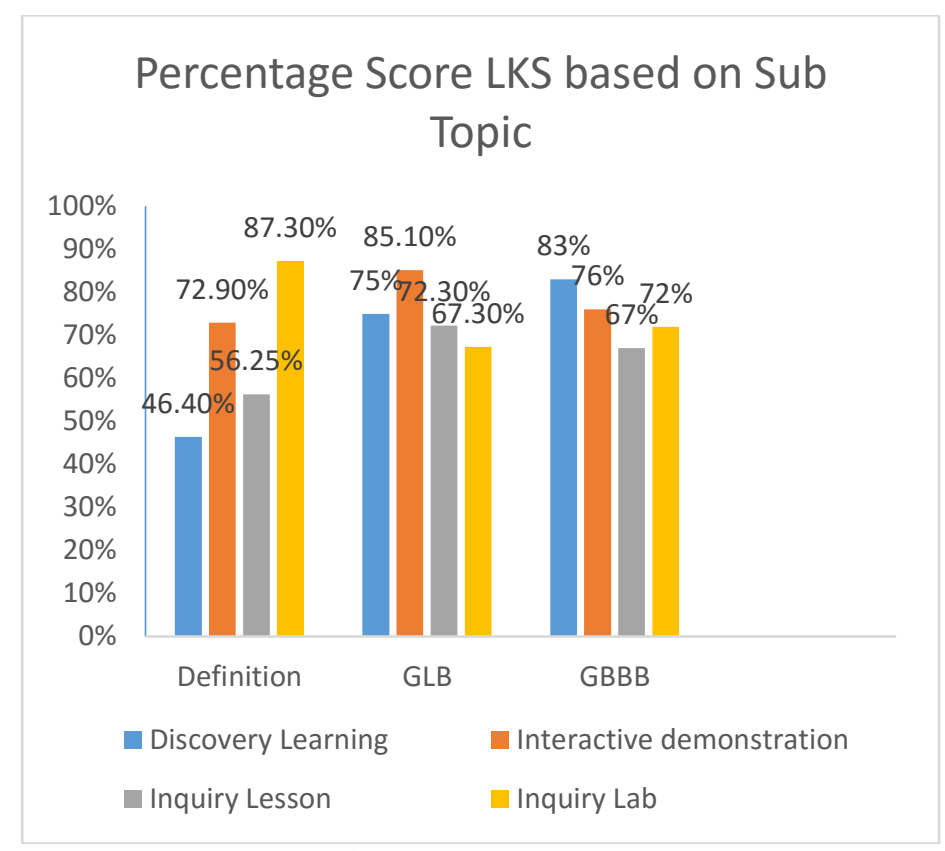

Fig 4. Percentage Score LKS

In contrast to findings in other sub-topics, where the subtopic of the sense of motion, the highest is inquiry lab and in uniform rectilinear motion is an interactive demonstration. This is possible because at the last meeting of students have started to understand the pedagogical goals of each stage of the inquiry levels. This is in line with the thinking [12] explains that to apply levels of inquiry requires a very long time to get used to and requires habituation so that students can construct their own knowledge.

Based on the student questionnaire responses, it can be said that almost all students $(86.7 \%)$ liked learning is done with the model levels of inquiry for various reasons, such as to be more active learning, fun, better understand the material presented, invented the concept itself and become more excited. This shows that students are ready to learn because it has been used to make the learning levels of inquiry and have a high motivation to do so during the retrieval of data.

Teacher response to the learning levels of inquiry was obtained by direct interviews. Based on the interview, the teacher model is very appreciated and give a good assessment of the learning is done because it is able to improve the critical thinking skills of students with theoretical got gradually so as to train the students' thinking. Regarding the students' responses, the teacher said that learning to do more fun for students because students are able to participate actively and passively, such as directly without previous learning activities.

Practical role in the learning levels of inquiry that have been done are able to make the students happy and motivating learning activities for students prefer the many activities carried out in comparison to listen to a lecture or theory that long. Based on observations and experience of conducting this study, he stated that this study can be done well because if 
there are limitations of the tool, teachers can replace it with animation or video learning associated with the material to be delivered.

Although the course was very nice, the teacher found such a study cannot be done by way of instant. Learning requires preparation, such as practical tools, worksheets, and other preparations that support the learning process. Constraints contained in the application of this study is the difficulty to introduce the learning stages with the stages quite long and sometimes make some students confused at the beginning of the application but can be overcome as the passage of this learning application at a later stage.

\section{CONCLUTION}

Based on the results of data analysis and discussions, it can be concluded that quantitatively there is an increase in aspects of levels of inquiry. The writer recommends several things, including 1) For teachers: the levels of inquiry model can be used as an alternative learning in science learning so that the students can construct their knowledge independently. 2) For other researchers: It would be better if the instrument student's worksheet on lives of inquiry is made to be more questions of each aspect so that it can be seen its consistency.

\section{ACKNOWLEDGMENT}

I would like to acknowledge Rika Siti Zahara's important contribution to this research.

\section{REFERENCES}

[1] Depdiknas. 2013. Panduan Mata Pelajaran IPA. Jakarta. 1

[2] Hofstein, A., \& Lunetta, V. N. (2004). The laboratory in science education: Foundations for the twenty-first century.Science Education, $88,28-54$.

[3] De Jong, T. \& van Joolingen, W. R. (1998). Scientific discovery learning with computer simulations of conceptual domains. Review of Educational Research, 68(2), 179-201.

[4] American Association for the Advancement of Science. (1993).Benchmarks of scientific literacy: Project 2061 report. New York: Oxford University Press.

[5] National Research Council. (1996). National Science Education Standards. Washington: National Academy Press.

[6] Wenning, C.J. (2010). Levels of inquiry: Using Spectrum learning sequences to teach science. Journal of Physics Teacher Education Online, 2(3), pp. 11-20.

[7] Wenning, C.J. (2011).A new Model for science teaching. Journal of Physics Teacher Education Online, 6(2), Summer 2011, pp. 1-20. Available:http://www.phy.ilstu.edu/pte/publications/A new Model for science_teaching.

[8] Wenning, C.J. (2005). Implementing inquiry-based instruction in the science classroom: A new model for solving the improvement-ofpractice problem. Journal of Physics Teacher Education Online, 2(4), pp. $9-158$

[9] Wenning, C.J. (2011). The Levels of inquiry Model of Science teaching. Journal of Physics Teacher Education Online, 6(2), pp. 9-16.

[10] Best, John. \& Kahn. (2006). Research in Education, Tenth Edition. Pearson Education Inc.

[11] Cresswell. (2009). Research Design, Qualitative, Quantitative and Mixed Methods Approaches, Third Edition. SAGE publications. Thousand Oaks California 91320.

[12] Wenning, C.J. (2005). Levels of inquiry: Hierarchies of pedagogical practices and inquiry processes. Journal of Physics Teacher Education Online, $2(3), \quad$ February $\quad 2005, \quad$ pp. $3-12$ 